in vivo $33: 2095-2102(2019)$

doi:10.21873/invivo.11709

\title{
Prognostic Impact of CD44 Expression in Patients With Myxofibrosarcoma
}

\author{
HIROYUKI TSUCHIE ${ }^{1}$, MAKOTO EMORI ${ }^{2}$, NAOHISA MIYAKOSHI ${ }^{1}$, HIROYUKI NAGASAWA $^{1}$, \\ KYOJI OKADA ${ }^{3}$, HIROSHI NANJYO ${ }^{4}$, YASUTAKA MURAHASHI ${ }^{2}$, EMI MIZUSHIMA ${ }^{2}$, \\ JUNYA SHIMIZU $^{2}$, TOSHIHIKO YAMASHITA ${ }^{2}$ and YOICHI SHIMADA ${ }^{1}$ \\ ${ }^{1}$ Department of Orthopedic Surgery, Akita University Graduate School of Medicine, Akita, Japan; \\ ${ }^{2}$ Department of Orthopedic Surgery, Sapporo Medical University School of Medicine, Hokkaido, Japan; \\ ${ }^{3}$ Department of Physical Therapy, Akita University Graduate School of Health Sciences, Akita, Japan; \\ ${ }^{4}$ Department of Pathology, Akita University Graduate School of Medicine, Akita, Japan
}

\begin{abstract}
Background/Aim: Abnormal expression of CD44 may promote cancer invasion. However, a limited number of studies have investigated the expression of CD44 in soft tissue sarcoma such as myxofibrosarcoma. We evaluated the relationship between expression of the standard form of CD44 (CD44s) and the clinical course of myxofibrosarcoma. Materials and Methods: Forty-four myxofibrosarcoma patients were retrospectively enrolled. Patient information including the proportion of CD44s-positive cells was collected, and multivariate analyses were conducted to determine the relationship between CD44s expression and clinicopathological factors. Results: Although CD44s did not affect prognosis, multivariate analysis indicated that high expression of CD44s predicted poor event-free survival $(p=0.004)$ and local recurrence $(p=0.049)$. CD44s expression was not associated with the occurrence of distant metastasis but was significantly higher in those with lung metastasis $(p=0.044)$. Conclusion: Increased expression of CD44s predicted poor event-free survival and local recurrence and was observed in myxofibrosarcoma patients with lung metastasis.
\end{abstract}

Myxofibrosarcoma is a common soft-tissue sarcoma found in the extremities of older adults and accounts for approximately $20 \%$ of all soft-tissue sarcomas (1). Although

This article is freely accessible online.

Correspondence to: Hiroyuki Tsuchie, MD, Department of Orthopedic Surgery, Akita University Graduate School of Medicine, 1-1-1 Hondo, Akita 010-8543, Japan. Tel: +81 188846148, Fax: +81 188362617, e-mail: tuchikiti@yahoo.co.jp

Key Words: Myxofibrosarcoma, CD44, metastasis, prognosis. complete surgical resection is the standard treatment, negative margins are difficult to obtain, since myxofibrosarcoma has an unusual infiltrative growth pattern along fascial plane (2). Therefore, myxofibrosarcoma outcomes are characterized by high local recurrence rates (15 to $57 \%$ ), leading to poor overall survival (3-8). In addition, distant metastases of myxofibrosarcoma are common. In particular, lung metastasis greatly affects prognosis (9). Although some factors associated with local recurrence, such as resection with positive or close margins and bone and joint involvement, have been examined in many studies, little is known regarding pre-existing factors that facilitate local recurrence or distant metastasis $(3-5,7,8)$.

Cell-cell and cell-matrix interactions are essential for normal cell growth and differentiation, and a variety of adhesion molecules participate in these interactions, including the hyaluronic acid binding transmembrane glycoprotein CD44. The standard form of CD44 (CD44s) and its variants are ubiquitously expressed on all cell types, where they act as receptors for hyaluronic acid. CD44 plays various roles and is involved in cellular differentiation, cellular migration, and cell-cell contact (10). Therefore, abnormal expression of CD44 in cancer and sarcoma cells may promote invasion and lead to local recurrence and distant metastases, ultimately affecting prognosis. Previous studies have reported the association between abnormal expression of CD44 and tumor growth or more aggressive behavior in various cancers, such as breast, gastric, colorectal, and lung cancer (11-14). However, relatively few studies have investigated the expression of CD44 in soft tissue sarcoma, with even fewer reports on myxofibrosarcoma (15-22).

The present study aimed to investigate the relationship between expression of CD44s and the clinical course of myxofibrosarcoma, such as prognosis, local recurrence, and distant metastasis. 


\section{Patients and Methods}

Subjects. Sixty patients with myxofibrosarcoma were treated at Akita University Hospital and Sapporo Medical University Hospital between 1992 and 2017. Among these, 44 consecutive patients who had sufficient medical records and tissue was available for pathological re-evaluation were included (19 males and 25 females; mean age, 72 years). Patient information, including age, sex, anatomical location, size of the tumor, proportion of CD44s-positive cells, metastasis at diagnosis, stage of the primary tumor, local and distant relapse, follow-up period, and outcome, was collected. Primary tumor stage was determined according to the staging system of the American Joint Committee on Cancer (AJCC), 7th edition (23). Specimens were classified according to the French Federation of Cancer Center Sarcoma Group (FNCLCC) system, which is based on mitotic index, necrosis extension, and histological differentiation of the tumor (24).

We examined factors influencing prognosis, event-free survival (EFS), local recurrence, and distant metastasis. The local recurrence-free survival and distant metastasis-free survival were defined as the time period for which patients remained free of local recurrence or distant metastasis after the primary tumor had been resected. EFS was defined as the time period for which patients remained free of local recurrence and distant metastasis after the primary tumor had been resected, and overall survival (OS) was defined as the time period from the date of diagnosis to that of death or the last follow-up. In the absence of any events, the date of the last follow-up was considered the end point. Since no deaths were reported due to postoperative complications in this study, patients who died from the original disease were considered to have died of disease (DOD). Cases were regarded to have had a surgical indication if all lesions, including distant metastases, could have been excised and if general anesthesia could have been administered by an anesthesiologist.

In patients with distant metastasis, we compared the expression of CD44s between individuals with lung metastasis (lung group) and those with lymph node metastasis (lymph node group).

This study was approved by the Institutional Review Board for Clinical Research at Akita university (approval number: 1794), and informed consent was obtained from all patients enrolled in the study.

Immunohistochemistry for CD44s. To evaluate the expression of CD44s, immunohistochemical staining was conducted on formalinfixed paraffin-embedded sections from 44 myxofibrosarcoma patients who underwent biopsy or resection, as previously described (25), using anti-CD44s antibody (dilution 1:800; Clone \#691534; R\&D Systems, Minneapolis, MN, USA). CD44s expression was quantified by two independent observers who were blinded to patient outcome, and the average of their measurements was used. A tumor was considered positive if staining was confined to the cell membrane or the cytoplasm in the absence of significant background staining. Ten randomized regions of interest (ROI) (size, $250 \mu \mathrm{m} \times 370 \mu \mathrm{m}$ each) were analyzed in the tumor, and the proportion of CD44s-positive cells was calculated and expressed as a percentage of total cells (26)

Statistical analysis. All continuous variables were expressed as means \pm standard deviations (SD). A Cox proportional hazards model was used to identify the factors associated with OS, EFS, local
Table I. Clinical information for 44 patients with myxofibrosarcoma.

\begin{tabular}{lc}
\hline Characteristic & Patients \\
\hline Number & 44 \\
Age (years) & $71.6 \pm 13.3$ \\
Gender - Male/Female & $19 / 25$ \\
Location - Extremity/Axial & $35 / 9$ \\
Size (mm) & $71.6 \pm 45.0$ \\
Past inappropriate excision - Present/None & $3 / 41$ \\
Metastasis at diagnosis - Present/None & $1 / 43$ \\
FNCLCC classification & \\
Grade I & 10 \\
Grade II & 20 \\
Grade III & 14 \\
AJCC stage & \\
Stage I & 10 \\
Stage II & 23 \\
Stage III & 10 \\
Stage IV & 1 \\
CD44s-positive cell rate (\%) & $34.6 \pm 20.4$ \\
Chemotherapy - Present/None & $3 / 41$ \\
Surgery - Present/None & $40 / 4$ \\
Surgical margin - Adequate/Inadequate & $29 / 11$ \\
Radiation - Present/None & $9 / 35$ \\
Metastasis after surgery - Present/None & $18 / 26$ \\
Local recurrence - Present/None & $14 / 26$ \\
Follow-up period (months) & $78.6 \pm 59.6$ \\
Outcome at last follow-up & \\
Alive without disease & 30 \\
Alive with disease & 5 \\
Deceased & 9 \\
\hline & \\
\hline &
\end{tabular}

Values are expressed as number of patients or mean $\pm \mathrm{SD}$ with ranges; FNCLCC: French Federation of Cancer Center Sarcoma Group.

recurrence, and distant metastasis. Student's $t$-tests, Welch t-tests, and Chi squared $\left(\chi^{2}\right)$ tests were used to compare characteristics between the lung and lymph node groups. Results with $p$-values less than 0.05 were considered significant.

\section{Results}

Patient demographic and clinicopathological information is shown in Table I. Metastasis at diagnosis was observed in the lung in one patient. According to the AJCC staging system, 3 (6.7\%), 7 (15.9\%), $11(25.0 \%), 12(27.3 \%), 10$ (22.7\%), and 1 $(2.5 \%)$ patients were classified as having stages IA, IB, IIA, II $\mathrm{B}$, III, and IV, respectively. All patients treated with chemotherapy received doxorubicin and ifosfamide. Immunohistochemical staining using anti-CD44s antibody showed both membranous and cytoplasmic staining (Figure 1). The CD44s-positive cell rate was $34.6 \pm 20.4 \%$. Eighteen of 44 patients $(40.9 \%)$ developed distant metastasis, including 12/18 patients $(66.7 \%)$ with pulmonary metastases, and $6 / 18$ with lymph node metastases. Among these 18 patients, there were one patient each with distant metastasis to bone, subcutaneous, 


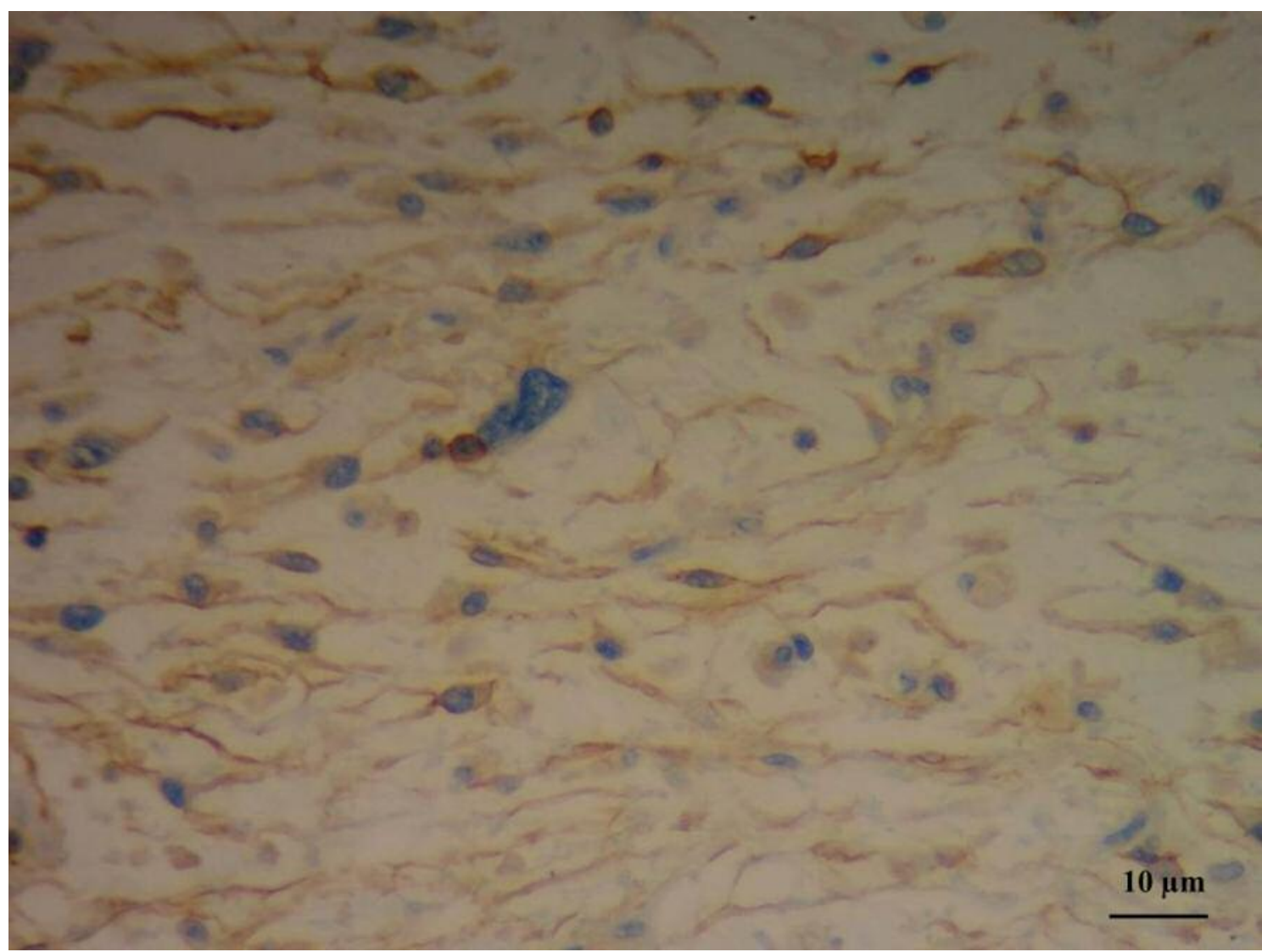

Figure 1. Representative images of immunostaining for CD44s. Original magnification, $x 400$.

Table II. Univariate and multivariate analysis of factors affecting event-free survival and prognosis.

\begin{tabular}{|c|c|c|c|c|c|c|}
\hline \multirow[t]{2}{*}{ Variables } & \multicolumn{3}{|c|}{ Univariate } & \multicolumn{3}{|c|}{ Multivariate } \\
\hline & OR & $95 \% \mathrm{CI}$ & $p$-Value & OR & $95 \% \mathrm{CI}$ & $p$-Value \\
\hline \multicolumn{7}{|l|}{ Event-free survival } \\
\hline Age & 1.026 & $0.989-1.064$ & 0.167 & & & \\
\hline Gender - Female & 0.481 & $0.214-1.080$ & 0.076 & & & \\
\hline Location - Axial & 1.447 & $0.574-3.649$ & 0.434 & & & \\
\hline Size & 1.004 & $0.997-1.012$ & 0.272 & & & \\
\hline FNCLCC classification & 1.767 & $0.982-3.181$ & 0.058 & & & \\
\hline Stage & 2.194 & $1.201-4.008$ & 0.011 & 2.214 & $1.212-4.044$ & 0.010 \\
\hline $\mathrm{CD} 44 \mathrm{~s}$ & 1.032 & $1.010-1.053$ & 0.003 & 1.030 & $1.010-1.051$ & 0.004 \\
\hline Radiation & 1.399 & $0.635-3.085$ & 0.405 & & & \\
\hline \multicolumn{7}{|l|}{ Prognosis } \\
\hline Age & 1.183 & $1.061-1.318$ & 0.002 & 1.174 & $1.036-1.330$ & 0.012 \\
\hline Gender - Female & 0.590 & $0.158-2.201$ & 0.432 & & & \\
\hline Location - axial & 1.051 & $0.217-5.089$ & 0.950 & & & \\
\hline Size & 1.005 & $0.993-1.018$ & 0.414 & & & \\
\hline FNCLCC classification & 1.961 & $0.724-5.309$ & 0.185 & & & \\
\hline Stage & 3.322 & $1.147-9.622$ & 0.027 & 1.132 & $0.383-3.342$ & 0.823 \\
\hline $\mathrm{CD} 44 \mathrm{~s}$ & 1.020 & $0.989-1.053$ & 0.212 & & & \\
\hline Radiation & 1.384 & $0.362-5.288$ & 0.635 & & & \\
\hline
\end{tabular}

OR: Odds ratio; 95\%CI: 95\% confidence interval; FNCLCC: French Federation of Cancer Center Sarcoma Group. 
in vivo 33: $2095-2102(2019)$

Table III. Univariate and multivariate analysis of factors affecting local recurrence-free survival and distant metastasis-free survival.

\begin{tabular}{|c|c|c|c|c|c|c|}
\hline \multirow[t]{2}{*}{ Variables } & \multicolumn{3}{|c|}{ Univariate } & \multicolumn{3}{|c|}{ Multivariate } \\
\hline & OR & $95 \% \mathrm{CI}$ & $p$-Value & OR & $95 \% \mathrm{CI}$ & $p$-Value \\
\hline \multicolumn{7}{|l|}{ Local recurrence } \\
\hline Age & 1.003 & $0.962-1.046$ & 0.894 & & & \\
\hline Gender - Female & 0.542 & $0.182-1.618$ & 0.272 & & & \\
\hline Location - Axial & 1.048 & $0.291-3.780$ & 0.943 & & & \\
\hline Size & 1.009 & $0.999-1.018$ & 0.077 & & & \\
\hline FNCLCC classification & 1.662 & $0.780-3.542$ & 0.188 & & & \\
\hline Stage & 1.993 & $0.913-4.349$ & 0.083 & & & \\
\hline CD44s & 1.036 & $1.010-1.062$ & 0.006 & & & \\
\hline Radiation & 1.971 & $0.677-5.741$ & 0.214 & & & \\
\hline \multicolumn{7}{|l|}{ Distant metastasis } \\
\hline Age & 1.063 & $1.003-1.127$ & 0.040 & 1.056 & $0.997-1.119$ & 0.063 \\
\hline Gender - Female & 0.482 & $0.162-1.439$ & 0.191 & & & \\
\hline Location - axial & 3.518 & $1.137-10.888$ & 0.029 & 3.018 & $0.957-9.521$ & 0.060 \\
\hline Size & 1.007 & $0.997-1.017$ & 0.172 & & & \\
\hline FNCLCC classification & 1.673 & $0.746-3.752$ & 0.212 & & & \\
\hline Stage & 2.354 & $0.971-5.706$ & 0.058 & & & \\
\hline $\mathrm{CD} 44 \mathrm{~s}$ & 1.012 & $0.988-1.037$ & 0.319 & & & \\
\hline Radiation & 1.055 & $0.344-3.236$ & 0.925 & & & \\
\hline
\end{tabular}

OR: Odds ratio; 95\%CI: 95\% confidence interval; FNCLCC: French Federation of Cancer Center Sarcoma Group.

intramuscular, and peritoneum involvement. No patient died of complications during the perioperative period. Radiotherapy was conducted in nine patients $(20.5 \%)$. Among these nine patients, heavy particle irradiation was conducted in one patient, and four of them received radiotherapy after surgical treatment because of insufficient surgical margin. The remaining four were irradiated for the purpose of local control since they did not wish to undergo surgical treatment or had difficulty in radical resection. Chemotherapy was administered to a total of three patients $(6.8 \%)$, and all of them were patients with distant metastasis.

In the univariate analysis to investigate factors associated with prognosis, older age and advanced stage were identified as risk factors for poor prognosis. Upon multivariate analysis, only older age was identified as a risk factor for poor prognosis $(p=0.012)$ (Table II). Upon univariate and multivariate analyses to investigate factors associated with EFS, advanced stage and high expression of CD44s predicted poor EFS ( $p=0.010$ and 0.004 , respectively) (Table II). In the univariate analysis to investigate factors associated with local recurrence, only high expression of CD44s was associated with local recurrence $(p=0.006)$ (Table III). In the univariate analysis, older age and trunk development were risk factors for distant metastasis, but no significant association was observed in the multivariate analysis (Table III). When we sub-analyzed solely the patients who received surgical treatment with adequate margin to accurately evaluate the relationship between CD44s and local
Table IV. Univariate analysis of factors affecting local recurrence-free survival only in patients who received surgical treatment with adequate margin.

\begin{tabular}{lccc}
\hline Variables & OR & $95 \%$ CI & $p$-Value \\
\hline Age & 0.979 & $0.928-1.034$ & 0.447 \\
Gender - Female & 0.640 & $0.128-3.207$ & 0.587 \\
Size & 1.002 & $0.982-1.024$ & 0.817 \\
FNCLCC classification & 2.175 & $0.633-7.470$ & 0.217 \\
Stage & 2.855 & $0.836-9.752$ & 0.094 \\
CD44s & 1.059 & $1.014-1.106$ & 0.010 \\
Radiation & 2.251 & $0.411-12.326$ & 0.350 \\
\hline
\end{tabular}

OR: Odds ratio; 95\%CI: 95\% confidence interval; FNCLCC: French Federation of Cancer Center Sarcoma Group.

recurrence, we found that high expression of CD44s was associated with local recurrence in the univariate analysis $(p=0.010)$ (Table IV).

Among the patients with distant metastasis, the proportion of

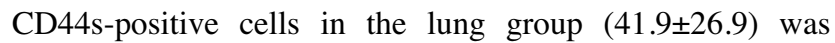
significantly higher than that in the lymph node group $(23.7 \pm 8.1) \quad(p=0.049)$. Similarly, the time from initial presentation to development of distant metastasis in the lung group (9.8 \pm 7.0 months) was significantly shorter than that in the lymph node group $(36.2 \pm 19.5$ months $)(p=0.024)$. Moreover, outcomes in the lung group were significantly poorer than those in the lymph node group $(p=0.005)$ (Table V). 
Table V. Univariate logistic regression analysis of lung and lymph node groups.

\begin{tabular}{|c|c|c|c|c|}
\hline & \multirow[t]{2}{*}{ Metastasis (-) } & \multicolumn{2}{|c|}{ Metastasis (+) } & \multirow[t]{2}{*}{$p$-Value } \\
\hline & & Lung & Lymph node & \\
\hline Number & 26 & 12 & 6 & \\
\hline Age (years) & $67.5 \pm 13.2$ & $79.1 \pm 11.1$ & $74.0 \pm 11.7$ & 0.383 \\
\hline Gender - Male/Female & $9 / 17$ & $6 / 6$ & $4 / 2$ & 0.867 \\
\hline Location - Extremity/Axial & $23 / 3$ & $8 / 4$ & $4 / 2$ & 0.600 \\
\hline Size $(\mathrm{mm})$ & $61.7 \pm 43.5$ & $84.9 \pm 54.4$ & $78.3 \pm 24.8$ & 0.785 \\
\hline Past inappropriate excision - Present/None & $3 / 23$ & $0 / 12$ & $0 / 6$ & - \\
\hline Metastasis at diagnosis - Present/None & $0 / 26$ & $1 / 11$ & $0 / 6$ & 0.716 \\
\hline FNCLCC grade & & & & 0.316 \\
\hline Grade I & 6 & 4 & 0 & \\
\hline Grades II and III & 20 & 8 & 6 & \\
\hline AJCC stage & & & & 0.617 \\
\hline Stages I and II & 24 & 6 & 3 & \\
\hline Stages III and IV & 2 & 6 & 3 & \\
\hline CD44s-positive cell rate & $33.0 \pm 18.1$ & $41.9 \pm 26.9$ & $23.7 \pm 8.1$ & 0.049 \\
\hline Chemotherapy - Present/None & $0 / 26$ & $2 / 11$ & $1 / 5$ & 0.545 \\
\hline Surgery - Present/None & $26 / 0$ & $9 / 3$ & $5 / 1$ & 0.841 \\
\hline Surgical margin - Adequate/Inadequate & $20 / 6$ & $5 / 4$ & $4 / 1$ & 0.739 \\
\hline Radiation - Present/None & $4 / 22$ & $3 / 9$ & $2 / 4$ & 0.852 \\
\hline Local Recurrence - Present/None & $7 / 19$ & $5 / 4$ & $2 / 3$ & 1.000 \\
\hline Time until first metastasis (month) & - & $9.8 \pm 7.0$ & $36.2 \pm 19.5$ & 0.024 \\
\hline Follow-up period (months) & $91.6 \pm 62.4$ & $38.0 \pm 42.0$ & $103.8 \pm 40.6$ & 0.006 \\
\hline Outcome at last follow-up & & & & 0.005 \\
\hline Alive without disease & 24 & 1 & 5 & \\
\hline Alive with disease & 0 & 4 & 1 & \\
\hline Deceased & 2 & 7 & 0 & \\
\hline
\end{tabular}

Values are expressed as the number of patients or mean \pm SD with ranges; FNCLCC: French Federation of Cancer Center Sarcoma Group.

\section{Discussion}

CD44 is involved in cellular differentiation and migration, and abnormal expression of CD44 in cancer and sarcoma cells may promote invasion and lead to local recurrence and distant metastases (11-22). In the present study, enhanced expression of CD44s was found to be a poor prognostic factor for local recurrence. In addition, the overall expression rate of $\mathrm{CD} 44 \mathrm{~s}$ in all patients was relatively high. Myxofibrosarcoma is a soft tissue sarcoma prone to local recurrence, and the expression of CD44s may have a major influence on its local infiltration. Prior to resection, if expression of CD44s is found to be elevated in the biopsy tissue, care should be taken when resecting the tumor with a sufficient margin, which may improve the prognosis of myxofibrosarcoma.

Conflicting results regarding the expression of CD44 in sarcoma have been reported. Although poor prognosis is associated with the overexpression of CD44v6, a variant form of $\mathrm{CD} 44$, discrepant results have been reported for CD44s (15-22, 27-34). Some studies of various types of soft tissue sarcoma have reported that high expression of CD44, including both standard and unknown forms, is likely to have adverse effects on prognosis, distant metastasis, and local recurrence, whereas other studies have reported good prognosis in patients with increased CD44s expression (1522). In terms of specific histological types of sarcoma, good prognosis is associated with the overexpression of CD44 in rhabdomyosarcoma (21). In contrast, no apparent association was observed between prognosis and CD44 expression in synovial sarcoma (22). To date, only one study has examined the relationship between CD44 expression and prognosis in patients with myxofibrosarcoma. Tumor tissues of 34 patients with myxofibrosarcoma were analyzed by PCR, and good prognosis was associated with increased CD44s and decreased CD44v6 expression (17). However, in this prior study, only CD44 expression and survival time were evaluated. Since various clinical factors, such as age, location, and tumor size, can also affect prognosis, it is necessary to analyze these factors together when examining the relationship between CD44 expression and prognosis. In our current study, we examined several factors that may affect prognosis. Consequently, we found that CD44s expression did not affect OS. However, increased CD44s 
expression was a risk factor for shorter EFS, and local recurrence. Our results thus differ somewhat from those of the earlier study.

A relatively large number of studies have been conducted on the expression of CD44 in malignant bone tumors, particularly osteosarcoma (27-33). In studies involving osteosarcoma, poor prognosis, as well as frequent distant metastasis and local recurrence, have been found to be associated with the overexpression of CD44s (30-32). In addition, in chondrosarcoma, poor prognosis was observed in patients with elevated CD44s (34). There has been only one report in which CD44s was not associated with the prognosis of patients with osteosarcoma (33), and there have been no reports showing a good prognosis in osteosarcoma patients with elevated CD44s. Although the relationship between CD44s and prognosis in our study differed from that of previous studies, our results are credible when considering past reports on various sarcomas.

The lung is generally thought to be the most frequent organ involved in the metastasis of soft tissue sarcoma. However, we have reported, in a previous study, that lymph node metastasis is also relatively frequent in patients with myxofibrosarcoma (9). In this study, various factors between patients with lung and lymph node metastasis were compared. Our results showed that the onset of lymph node metastasis was later than that of lung metastasis and that the prognosis of lymph node metastasis patients was better than that of lung metastasis patients. However, in our previous study, we were unable to identify factors associated with these clinical features (9). In the current study, CD44s expression was evaluated in patients with distant metastasis and found that CD44s expression was significantly elevated in patients with lung metastasis compared with that in patients with lymph node metastasis. He et al. have reported that the expression of CD44 was elevated in patients with lung metastasis of osteosarcoma (31). This is similar to the results of our study, indicating that the upregulation of CD44s may be a risk factor for pulmonary metastasis.

Aside from CD44, few reports have examined cell surface markers that affect the prognosis of myxofibrosarcoma. CD109 is a monomeric $170-\mathrm{kDa}$ cell surface glycoprotein that is a TGF- $\beta$ co-receptor, regulating TGF- $\beta$ receptor endocytosis and degradation (35). Increased expression of CD109 has been reported to be a poor prognostic factor for myxofibrosarcoma (36).

One of the main limitations of this study was the inclusion of a relatively small number of myxofibrosarcoma patients. Since only a few patients underwent chemotherapy and radiotherapy, the number of patients was limited, and thus, it was difficult to strictly evaluate detailed treatment. Additionally, CD44s expression in the lung metastasis patients was found to be higher than that in the lymph node metastasis patients. However, expression of CD44s was not determined as a factor affecting OS, and the small number of patients may have influenced this conflicting result. Although the number of cases in the present study was larger than that of a previous study evaluating CD44 expression in myxofibrosarcoma (21), more cases are needed for a comprehensive multivariate analysis of the various factors affecting prognosis.

The present study demonstrates that increased expression of CD44s is a risk factor for shorter EFS and local recurrence. In addition, expression of CD44s was significantly elevated in patients with lung metastasis. However, CD44s expression was not a predictor of OS. More detailed studies on the influence of CD44 expression on prognosis and distant metastasis of myxofibrosarcoma are necessary in the future.

\section{Conflicts of Interest}

The Authors have no conflicts of interest to declare regarding this study.

\section{Authors' Contributions}

All Authors were involved in the planning and revising for this research; Tsuchie $H$, Nagasawa $H$, Emori $M$, Murahasi $Y$, Mizushima E, and Shimizu J collected the clinical data; Emori M and Nanjyo $\mathrm{H}$ made a preparation for immunostaining; Nanjyo $\mathrm{H}$ and Okada $\mathrm{K}$ evaluated immunostaining; Tsuchie $\mathrm{H}$ analyzed the raw data; Tsuchie $\mathrm{H}$ wrote this dissertation; Miyakoshi N, Yamashita $\mathrm{Y}$, and Shimada Y reviewed this dissertation.

\section{References}

1 Mentzel T, Hogendoorn PCW and Huang HY: Myxofibrosarcoma. In: WHO Classification of Tumours of Soft Tissue and Bone. Fletcher CDM, Bridge JA, Hogendoorn PCW, Mertens F (eds.). Lyon: IARC Press, pp. 93-94, 2013.

2 Manoso MW, Pratt J, Healey JH, Boland PJ and Athanasian EA: Infiltrative MRI pattern and incomplete initial surgery compromise local control of myxofibrosarcoma. Clin Orthop Relat Res 450: 89-94, 2006. PMID: 16801862. DOI: 10.1097/01.blo.0000229292.98850.14

3 Sanfilippo R, Miceli R, Grosso F, Fiore M, Puma E, Pennacchioli E, Barisella M, Sangalli C, Mariani L, Casali PG and Gronchi A: Myxofibrosarcoma: prognostic factors and survival in a series of patients treated at a single institution. Ann Surg Oncol 18(3): 720-725, 2011. PMID: 20878245. DOI: 10.1245/s10434-010-1341-4

4 Kaya M, Wada T, Nagoya S and Yamashita T: Bone and/or joint attachment is a risk factor for local recurrence of myxofibrosarcoma. J Orthop Sci 16(4): 413-417, 2011. PMID: 21611802. DOI: $10.1007 / \mathrm{s} 00776-011-0100-0$

5 Dewan V, Darbyshire A, Sumathi V, Jeys L and Grimer R: Prognostic and survival factors in myxofibrosarcomas. Sarcoma 2012: 830879, 2012. PMID: 22736953. DOI: 10.1155/2012/830879

6 Mutter RW, Singer S, Zhang Z, Brennan MF and Alektiar KM: The enigma of myxofibrosarcoma of the extremity. Cancer 118(2): 518527, 2012. PMID: 21717447. DOI: 10.1002/cncr.26296 
7 Look Hong NJ, Hornicek FJ, Raskin KA, Yoon SS, Szymonifka J, Yeap B, Chen YL, DeLaney TF, Nielsen GP and Mullen JT: Prognostic factors and outcomes of patients with myxofibrosarcoma. Ann Surg Oncol 20(1): 80-86, 2013. PMID: 22890594. DOI: 10.1245/s10434-012-2572-3

8 Kikuta K, Kubota D, Yoshida A, Suzuki Y, Morioka H, Toyama Y, Kobayashi E, Nakatani F, Chuuman H and Kawai A: An analysis of factors related to recurrence of myxofibrosarcoma. Jpn J Clin Oncol 43(11): 1093-1104, 2013. PMID: 23969617. DOI: $10.1093 /$ jjco/hyt 119

9 Tsuchie H, Kaya M, Nagasawa H, Emori M, Murahashi Y, Mizushima E, Miyakoshi N, Yamashita $\mathrm{T}$ and Shimada Y: Distant metastasis in patients with myxofibrosarcoma. Ups J Med Sci 122(3): 190-193, 2017. PMID: 28814152. DOI: 10.1080/03009734.2017.1356404

$10 \mathrm{Li} \mathrm{Y}$ and Heldin P: Hyaluronan production increases the malignant properties of mesothelioma cells. Br J Cancer 85(4): 600-607, 2001. PMID: 11506502. DOI: 10.1054/bjoc.2001.1922

11 Joensuu H, Klemi PJ, Toikkanen S and Jalkanen S: Glycoprotein CD44 expression and its association with survival in breast cancer. Am J Pathol 143(3): 867-874, 1993. PMID: 8362982.

12 Nishimura S, Chung YS, Yashiro M, Inoue T and Sowa M: CD44H plays an important role in peritoneal dissemination of scirrhous gastric cancer cells. Jpn J Cancer Res 87(12): 1235-1244, 1996. PMID: 9045958. DOI: 10.1111/j.1349-7006.1996.tb03138.x

13 Nihei Z, Ichikawa W, Kojima K, Togo S, Miyanaga T, Hirayama $\mathrm{R}$ and Mishima $\mathrm{Y}$ : The positive relationship between the expression of CD44 variant 6 and prognosis in colorectal cancer. Surg Today 26(9): 760-761, 1996. PMID: 8883258.

14 Washimi O, Ueda R, Ariyoshi Y, Suyama M, Seki T, Takahashi $\mathrm{T}$ and Takahashi T: Expression of CD44 variant isoforms in normal and neoplastic cells of the lung. Jpn J Cancer Res 85(11): 1112-1116, 1994. PMID: 7530240. DOI: 10.1111/j.13497006.1994.tb02915.x

15 Kahara N, Ozaki T, Doi T, Nishida K, Kawai A, Shibahara M and Inoue H: CD44 expression in soft tissue sarcomas. Virchows Arch 436(6): 574-578, 2000. PMID: 10917171.

16 Maula S, Huuhtanen RL, Blomqvist CP, Wiklund TA, Laurila P and Ristamäki R: The adhesion molecule CD44v6 is associated with a high risk for local recurrence in adult soft tissue sarcomas. Br J Cancer 84(2): 244-252, 2001. PMID: 11161384 DOI: $10.1054 /$ bjoc. 2000.1590

17 Matuschek C, Lehnhardt M, Gerber PA, Poremba C, Hamilton J, Lammering G, Orth K, Budach W, Bojar H, Bölke E and Peiper M: Increased CD44s and decreased CD44v6 RNA expression are associated with better survival in myxofibrosarcoma patients: a pilot study. Eur J Med Res 19: 6, 2014. PMID: 24491153. DOI: 10.1186/2047-783X-19-6

18 Engellau J, Bendahl PO, Persson A, Domanski HA, Akerman M, Gustafson P, Alvegård TA, Nilbert M and Rydholm A: Improved prognostication in soft tissue sarcoma: independent information from vascular invasion, necrosis, growth pattern, and immunostaining using whole-tumor sections and tissue microarrays. Hum Pathol 36: 994-1002, 2005. PMID: 16153463. DOI: 10.1016/ j.humpath.2005.07.008

19 Henderson T, Chen M, Darrow MA, Li CS, Chiu CL, Monjazeb AM, Murphy WJ and Canter RJ: Alterations in cancer stem-cell marker CD44 expression predict oncologic outcome in softtissue sarcomas. J Surg Res 223: 207-214, 2018. PMID: 29433875. DOI: $10.1016 /$ j.jss.2017.11.016
20 Peiper M, Sato T, Zurakowski D, Eisenberger C, Heinecke A, Hosch S and Knoefel WT: CD44s expression is associated with improved survival in soft tissue sarcoma. Anticancer Res 24(2C): 1053-1056, 2004. PMID: 15154622.

21 Humphrey G, Hazel DL, MacLennan K and Lewis I: Expression of CD44 by rhabdomyosarcoma: a new prognostic marker? Br J Cancer 80(5-6): 918-921, 1999. PMID: 10360676. DOI: 10.1038/sj.bjc.6690442

22 Sneath RJ and Mangham DC: CD44 isoform expression in synovial sarcoma correlates with epitheliogenesis but not prognosis. Histopathology 37: 166-174, 2000. PMID: 10931241.

23 Edge SB and Compton CC (eds): AJCC Cancer Staging Handbook, 7th ed. New York: Springer, 2010.

24 Coindre JM, Terrier P, Bui NB, Bonichon F, Collin F, Le Doussal V, Mandard AM, Vilain MO, Jacquemier J, Duplay H, Sastre X, Barlier C, Henry-Amar M, Macé-Lesech J and Contesso G: Prognostic factors in adult patients with locally controlled soft tissue sarcoma. A study of 546 patients from the French Federation of Cancer Centers Sarcoma Group. J Clin Oncol 14(3): 869-877, 1996. PMID: 8622035. DOI: 10.1200/JCO.1996.14.3.869

25 Heyse TJ, Malcherczyk D, Moll R, Timmesfeld N, Wapelhorst J, Fuchs-Winkelmann S, Paletta JR and Schofer MD: CD44: survival and metastasis in chondrosarcoma. Osteoarthritis Cartilage 18(6): 849-856, 2010. PMID: 20171296. DOI: 10.1016/j.joca.2010.02.007

26 Tsuchie H, Miyakoshi N, Kasukawa Y, Aonuma H and Shimada Y: Intermittent administration of human parathyroid hormone before osteosynthesis stimulates cancellous bone union in ovariectomized rats. Tohoku J Exp Med 229(1): 19-28, 2013. PMID: 23221107. DOI: 10.1620/tjem.229.19

27 Kuryu M, Ozaki T, Nishida K, Shibahara M, Kawai A and Inoue $\mathrm{H}$ : Expression of CD44 variants in osteosarcoma. J Cancer Res Clin Oncol 125(11): 646-652, 1999. PMID: 10541973.

28 Deng Z, Niu G, Cai L, Wei $R$ and Zhao X: The prognostic significance of CD44V6, CDH11, and $\beta$-catenin expression in patients with osteosarcoma. Biomed Res Int 2013: 496193, 2013. PMID: 23971040. DOI: 10.1155/2013/496193

29 Zhang Y, Ding C, Wang J, Sun G, Cao Y, Xu L, Zhou L and Chen X: Prognostic significance of CD44V6 expression in osteosarcoma: a meta-analysis. J Orthop Surg Res 10: 187, 2015. PMID: 26697855. DOI: 10.1186/s13018-015-0328-z

30 Gvozdenovic A, Arlt MJ, Campanile C, Brennecke P, Husmann K, Li Y, Born W, Muff R and Fuchs B: CD44 enhances tumor formation and lung metastasis in experimental osteosarcoma and is an additional predictor for poor patient outcome. J Bone Miner Res 28(4): 838-847, 2013. PMID: 23169460. DOI: 10.1002/jbmr.1817

31 He A, Yang X, Huang Y, Feng T, Wang Y, Sun Y, Shen Z and Yao Y: CD133(+) CD44(+) Cells Mediate in the Lung Metastasis of Osteosarcoma. J Cell Biochem 116(8): 1719-1729, 2015. PMID: 25736420. DOI: $10.1002 /$ jcb.25131

32 Gao Y, Feng Y, Shen JK, Lin M, Choy E, Cote GM, Harmon DC, Mankin HJ, Hornicek FJ and Duan Z: CD44 is a direct target of miR-199a-3p and contributes to aggressive progression in osteosarcoma. Sci Rep 5: 11365, 2015. PMID: 26079799. DOI: $10.1038 /$ srep 11365

33 Liu Y, Wu Y, Gu S, Sun Z, Rui Y, Wang J, Lu Y, Li H, Xu K and Sheng P: Prognostic role of CD44 expression in osteosarcoma: evidence from six studies. Diagn Pathol 9: 140, 2014. PMID: 25112408. DOI: 10.1186/1746-1596-9-140 
34 Heyse TJ, Malcherczyk D, Moll R, Timmesfeld N, Wapelhorst J, Fuchs-Winkelmann S, Paletta JR and Schofer MD: CD44: survival and metastasis in chondrosarcoma. Osteoarthritis Cartilage 18(6): 849-856, 2010. PMID: 20171296. DOI: 10.1016/j.joca.2010.02.007

35 Bizet AA, Liu K, Tran-Khanh N, Saksena A, Vorstenbosch J, Finnson KW, Buschmann MD and Philip A: The TGF- $\beta$ coreceptor, CD109, promotes internalization and degradation of TGF- $\beta$ receptors. Biochim Biophys Acta 1813(5): 742-753, 2011. PMID: 21295082. DOI: 10.1016/j.bbamcr.2011.01.028
36 Emori M, Tsukahara T, Murata K, Sugita S, Sonoda T, Kaya M, Soma T, Sasaki M, Nagoya S, Hasegawa T, Wada T, Sato N and Yamashita T: Prognostic impact of CD109 expression in myxofibrosarcoma. J Surg Oncol 111(8): 975-979, 2015. PMID: 26031650. DOI: 10.1002 /jso.23934

Received July 31, 2019

Revised August 12, 2019

Accepted August 14, 2019 